\title{
Hazardous Materials
} Verification and Limited Characterization Report on Sodium and Caustic Residuals in Materials and Fuel Complex Facilities MFC-799/799A

August 2010

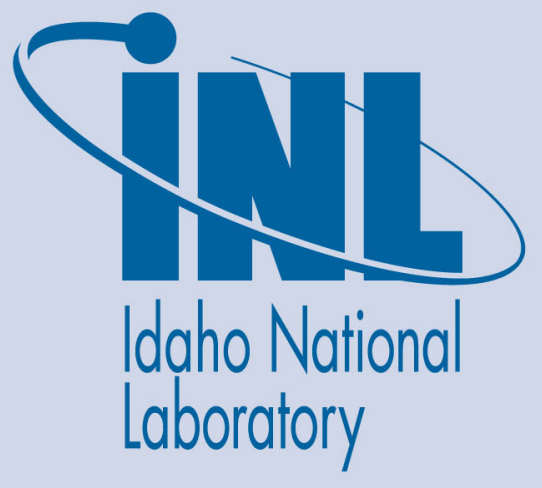

The INL is a U.S. Department of Energy National Laboratory operated by Battelle Energy Alliance 


\section{DISCLAIMER}

This information was prepared as an account of work sponsored by an agency of the U.S. Government. Neither the U.S. Government nor any agency thereof, nor any of their employees, makes any warranty, expressed or implied, or assumes any legal liability or responsibility for the accuracy, completeness, or usefulness, of any information, apparatus, product, or process disclosed, or represents that its use would not infringe privately owned rights. References herein to any specific commercial product, process, or service by trade name, trade mark, manufacturer, or otherwise, does not necessarily constitute or imply its endorsement, recommendation, or favoring by the U.S. Government or any agency thereof. The views and opinions of authors expressed herein do not necessarily state or reflect those of the U.S. Government or any agency thereof. 


\section{Hazardous Materials Verification and Limited Characterization Report on Sodium and Caustic Residuals in Materials and Fuel Complex Facilities MFC-799/799A}

August 2010

Idaho National Laboratory Idaho Falls, Idaho 83415

http://www.inl.gov

Prepared for the

U.S. Department of Energy

Office of Nuclear Energy

Under DOE Idaho Operations Office

Contract DE-AC07-05ID14517 



\begin{abstract}
This report is a companion to the Facilities Condition and Hazard Assessment for Materials and Fuel Complex Sodium Processing Facilities MFC-799/799A and Nuclear Calibration Laboratory MFC-770C (referred to as the Facilities Condition and Hazards Assessment). This report specifically responds to the requirement of Section 9.2, Item 6, of the Facilities Condition and Hazards Assessment to provide an updated assessment and verification of the residual hazardous materials remaining in the Sodium Processing Facilities processing system. The hazardous materials of concern are sodium and sodium hydroxide (caustic).

The information supplied in this report supports the end-point objectives identified in the Transition Plan for Multiple Facilities at the Materials and Fuels Complex, Advanced Test Reactor, Central Facilities Area, and Power Burst Facility, as well as the deactivation and decommissioning critical decision milestone 1, as specified in U.S. Department of Energy Guide 413.3-8, "Environmental Management Cleanup Projects."
\end{abstract}

Using a tailored approach and based on information obtained through a combination of process knowledge, emergency management hazardous assessment documentation, and visual inspection, this report provides sufficient detail regarding the quantity of hazardous materials for the purposes of facility transfer; it also provides that further characterization/verification of these materials is unnecessary. 


\section{CONTENTS}

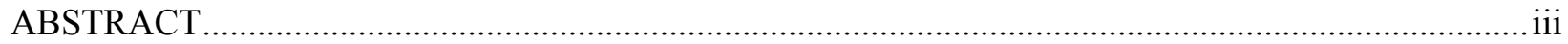

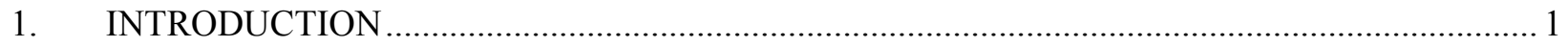

2. APPROACH

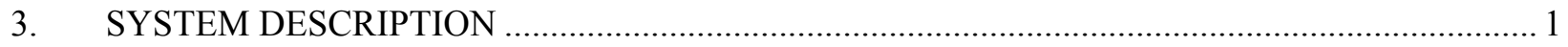

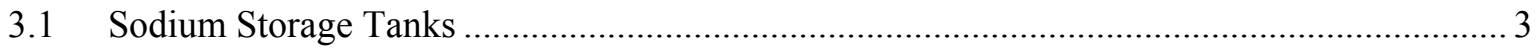

3.2 Sodium Reaction Vessel (A23-T-201) ..................................................................... 3

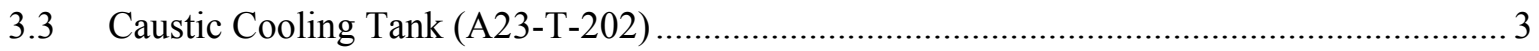

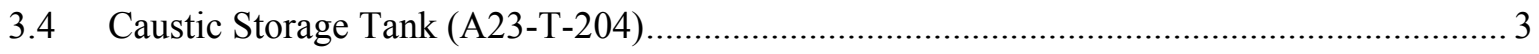

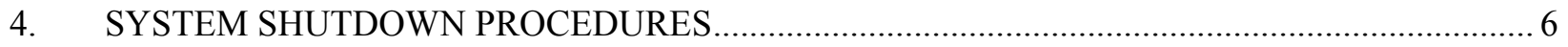

5. RESIDUAL HAZARDOUS MATERIAL QUANTITIES ….................................................. 7

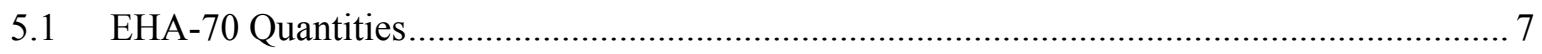

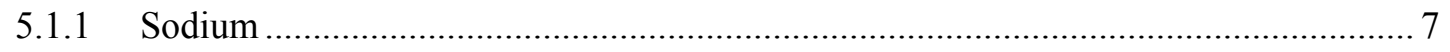

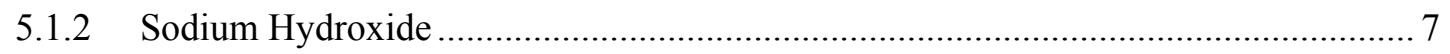

5.2 Resource Conservation and Recovery Act Permit Quantities .......................................... 7

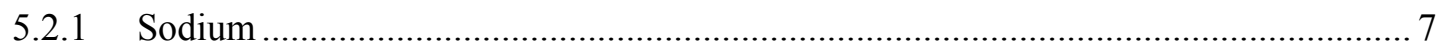

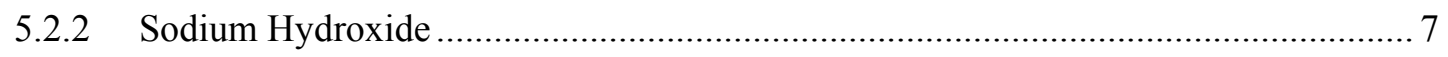

5.3 Material Confirmation Measurements ............................................................................. 7

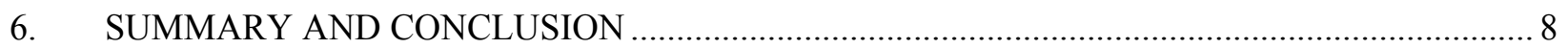

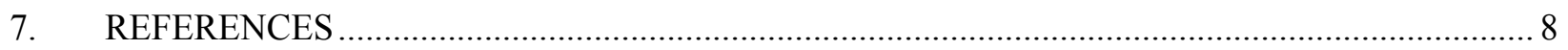

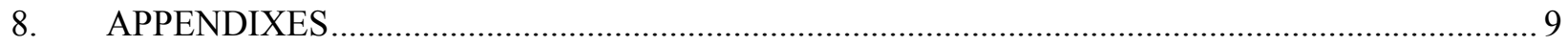

Appendix A, Sodium Process Facility General Arrangement Drawing ........................................ 10

Appendix B, Sodium Process Facility Sodium Process Piping and Instrumentation

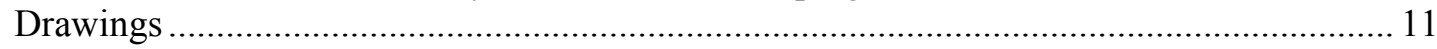




\section{FIGURES}

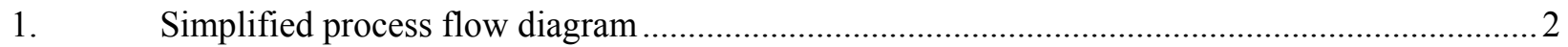

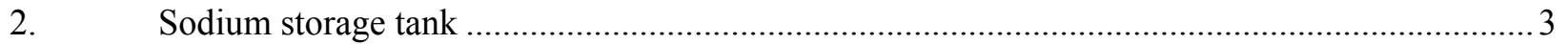

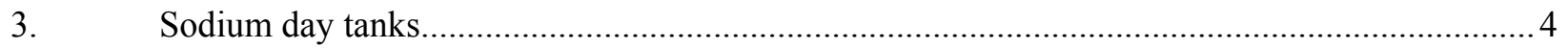

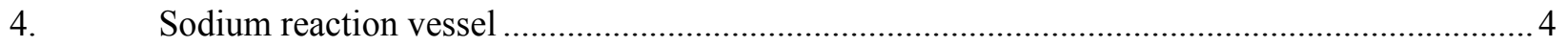

5. Sodium reaction vessel recirculation pumps and piping ….............................................

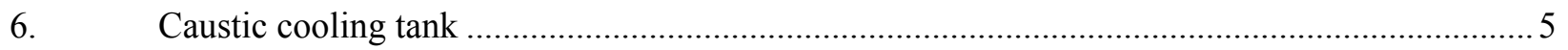

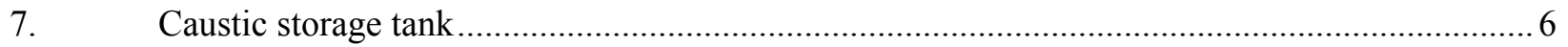




\section{Hazardous Materials Verification and Limited Characterization Report on Sodium and Caustic Residuals in Materials and Fuel Complex Facilities MFC-799/799A}

\section{INTRODUCTION}

This report is a companion to the Facilities Condition and Hazard Assessment for Materials and Fuel Complex Sodium Processing Facilities MFC-799/799A and Nuclear Calibration Laboratory MFC-770C (INL 2009; referred to as the Facilities Condition and Hazards Assessment). This report specifically responds to the requirement of Section 9.2, Item 6, of the Facilities Condition and Hazards Assessment to provide an updated assessment and verification of the residual hazardous materials remaining in the Sodium Processing Facilities processing system. The hazardous materials of concern are sodium and sodium hydroxide (caustic).

The information supplied in this report supports the end-point objectives identified in the Transition Plan for Multiple Facilities at the Materials and Fuels Complex, Advanced Test Reactor, Central Facilities Area, and Power Burst Facility (INL 2010), as well as the deactivation and decommissioning critical decision milestone 1, as specified in U.S. Department of Energy (DOE) Guide 413.3-8, "Environmental Management Cleanup Projects."

\section{APPROACH}

DOE Guide 450.3-3, "Tailoring for Integrated Safety Management Applications," demonstrates that tailoring is integral to the Integrated Safety Management System. Application of tailoring is appropriate for all phases of facility transitioning.

In keeping with tailoring principles, reliance on information compiled from the following sources, as opposed to intrusive sampling, is an adequate and prudent approach to meet the objectives of this report:

- Process knowledge relative to tank and pumping configurations and the procedures followed when the facilities were placed into operational standby

- Information contained in EHA-70, Appendix R, "Emergency Management Hazards Assessment for MFC-799, Sodium Process Facility, and MFC-799A, Caustic Storage Tank Building"

- Confirmation measurements of materials, where practical.

\section{SYSTEM DESCRIPTION}

Residual hazardous materials are confined to the system process components depicted in the simplified process flow diagram in Figure 1. The Facilities Condition and Hazards Assessment (INL 2009) provides a detailed description of the MFC-799/799A equipment and process from which the following summary is extracted. 


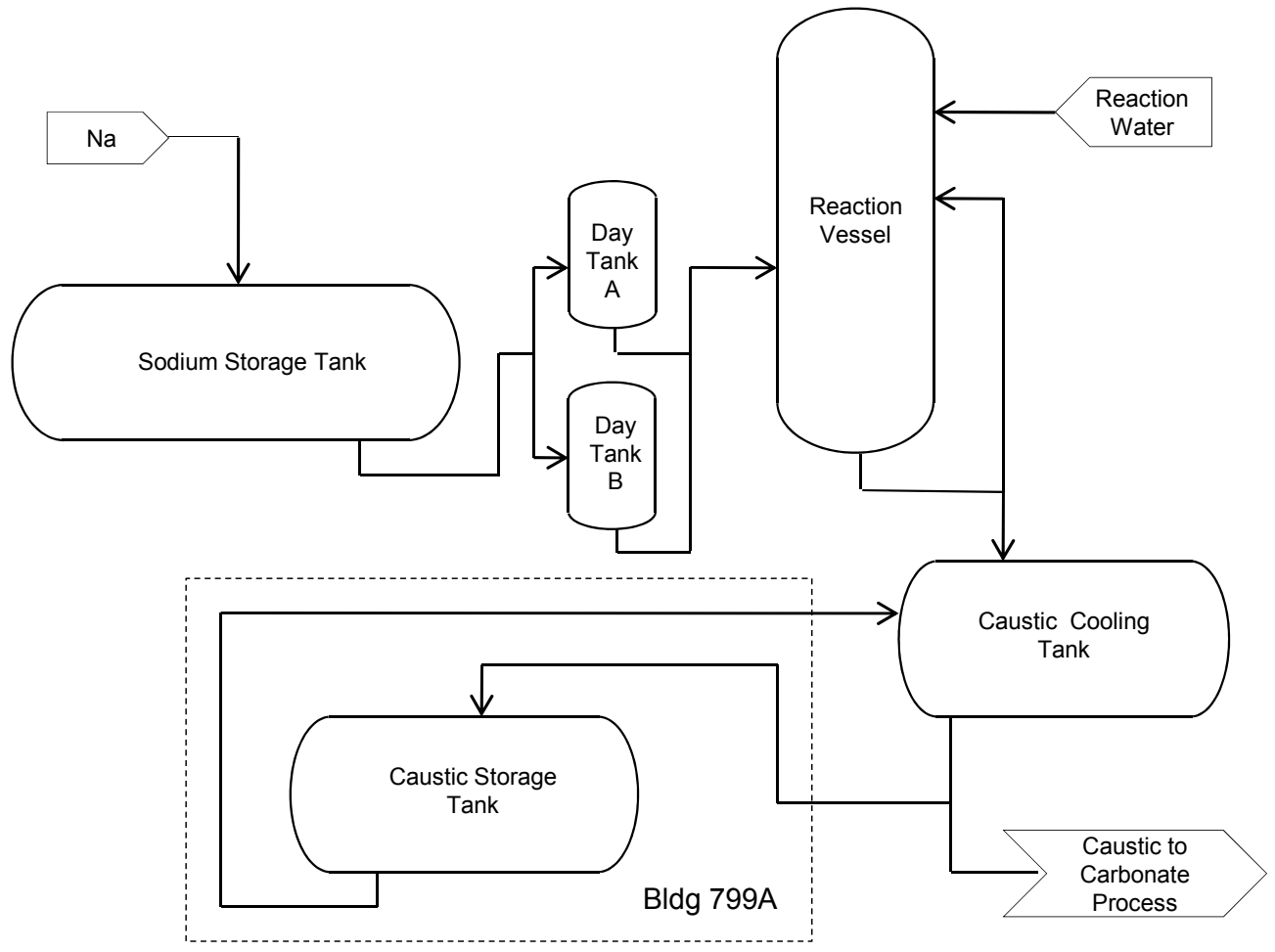

Figure 1. Simplified process flow diagram.

The Sodium Process Equipment Area was used to store and treat alkali metal hazardous waste/mixed waste. There are several major components in the sodium process area, including a 5,000-gal sodium storage tank, two 730-gal sodium day tanks (Tank A on the west side and Tank B on the east), sodium reaction vessel, 1,000-gal caustic cooling tank, and a 4,000-gal caustic storage tank.

The sodium storage tank received alkali metal from the barrel drain stations (supply lines are all drained). The storage tank filled the day tanks, which fed the alkali metal to the reaction vessel.

The reaction vessel converted the alkali metal to a liquid hydroxide waste form, which was then loaded into drums and allowed to cool to solidify. The caustic cooling tank and the caustic storage tank allowed for storage of caustic during reaction vessel shutdowns. The caustic storage tank was included to provide for backup storage only. The caustic storage tank is located in a separate building (MFC-799A) just west of the Sodium Process Equipment Area.

Pressurized nitrogen gas was the motive force for transfer of sodium to the reaction vessel, whereas pumps were used to transfer and recirculate caustic within the system.

In the reaction vessel, the sodium/sodium potassium reacted with water to produce sodium hydroxide/potassium hydroxide and hydrogen. The hydroxide in the reaction vessel was recirculated with approximately 1 to 2 gallons per minute (gpm) of the 8 to 10 gpm recirculated solution continuously diverted to either the drum fill station (during operation) or to the 1,000-gal caustic cooling tank (during shutdown operations).

The caustic metering pump transferred the $50 \mathrm{wt} \%$ hydroxide solution from the 1,000 -gal caustic cooling tank directly to the reaction vessel upon startup or if backup hydroxide storage was needed. The 4,000-gal caustic storage tank was intended to be used, in an emergency only, to transfer hydroxide solution to or from the caustic storage tank to the reaction vessel. The caustic recirculation pump, metering pump, and caustic cooling tank are located in the sodium process area; the caustic storage tank and caustic transfer pump are housed in MFC-799A. 
Drawing W7990-0207-ED-01, Sodium Process Facility Building 799 General Arrangement (see Appendix A), depicts the layout of these system components. Each of the tanks and the reaction vessel are installed in below-grade, lined containment wells with associated recirculation and pumping equipment mounted below the vessel bottoms, all of which allows for gravity draining of the systems.

\subsection{Sodium Storage Tanks}

Figures 2 and 3 show the 5,000-gal sodium storage tank (A1-T-101) and the two 750-gal sodium day tanks (A1-T-102 and A1-T-103), respectively.

As depicted in drawing E5274-0013-ED-19, Sheet 1 of 4, Sodium Process Facility, Sodium Process Piping and Instrumentation Diagram (see Appendix B), all three tanks have rounded bottoms and the sodium storage tank has a dip tube well on the end closest to the day tanks. All three tanks have low point drain ports.

\subsection{Sodium Reaction Vessel (A23-T-201)}

Figure 4 shows the sodium reaction vessel and Figure 5 depicts the associated recirculation pumps.

The sodium reaction vessel also has a rounded bottom and drains to the recirculation pump from the low point (see drawing E5274-0013-ED-19, Sheet 2 of 4, Sodium Process Facility, Sodium Process Piping and Instrumentation Diagram [see Appendix B]).

\subsection{Caustic Cooling Tank (A23-T-202)}

Figure 6 shows the 1,000-gal caustic cooling tank. This tank also has a round bottom and drains at the tank low point (see drawing E4-5274-0013-ED-19, Sheet 3 of 4, Sodium Process Facility, Sodium Process Piping and Instrumentation Diagram [see Appendix B]).

\subsection{Caustic Storage Tank (A23-T-204)}

Figure 7 shows the 4,000-gal caustic storage tank located in MFC-799A and is depicted in drawing E4-5274-0013-ED-19, Sheet 3 of 4, Sodium Process Facility, Sodium Process Piping and Instrumentation Diagram (see Appendix B). It also has a round bottom and drains from the tank low point.

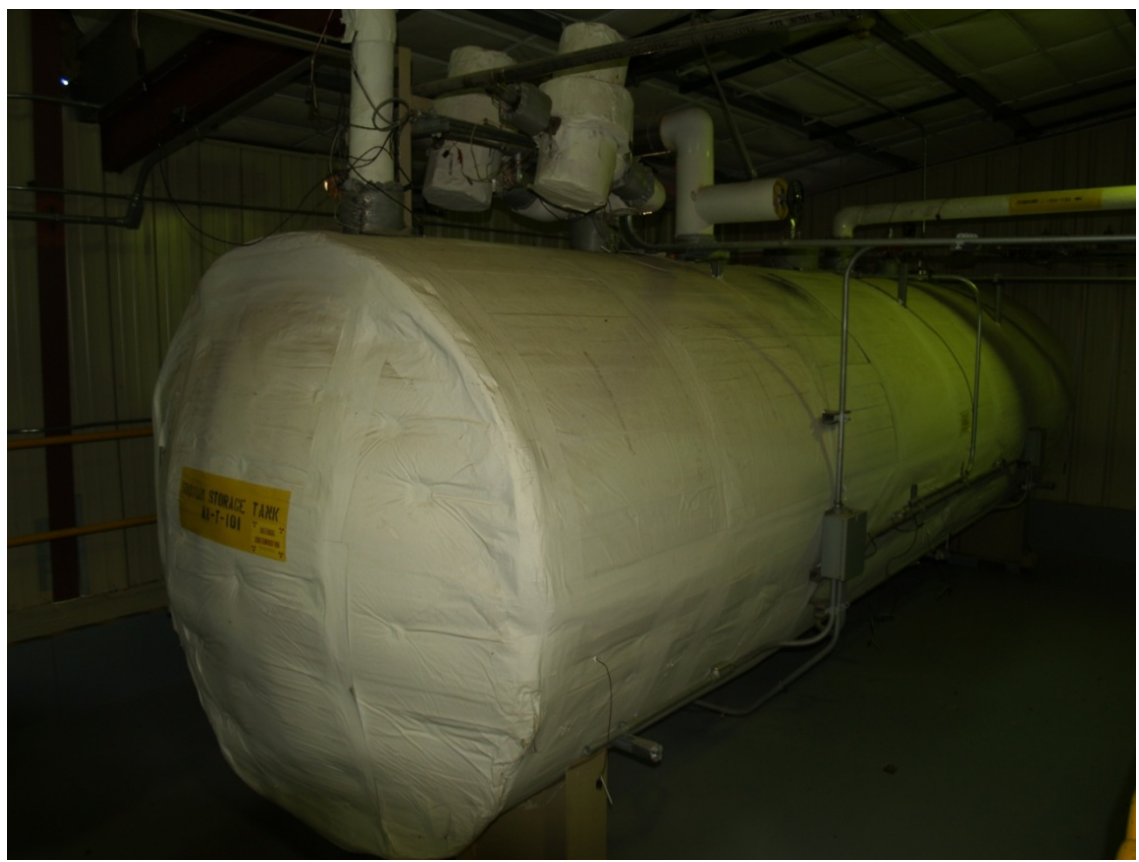

Figure 2. Sodium storage tank. 


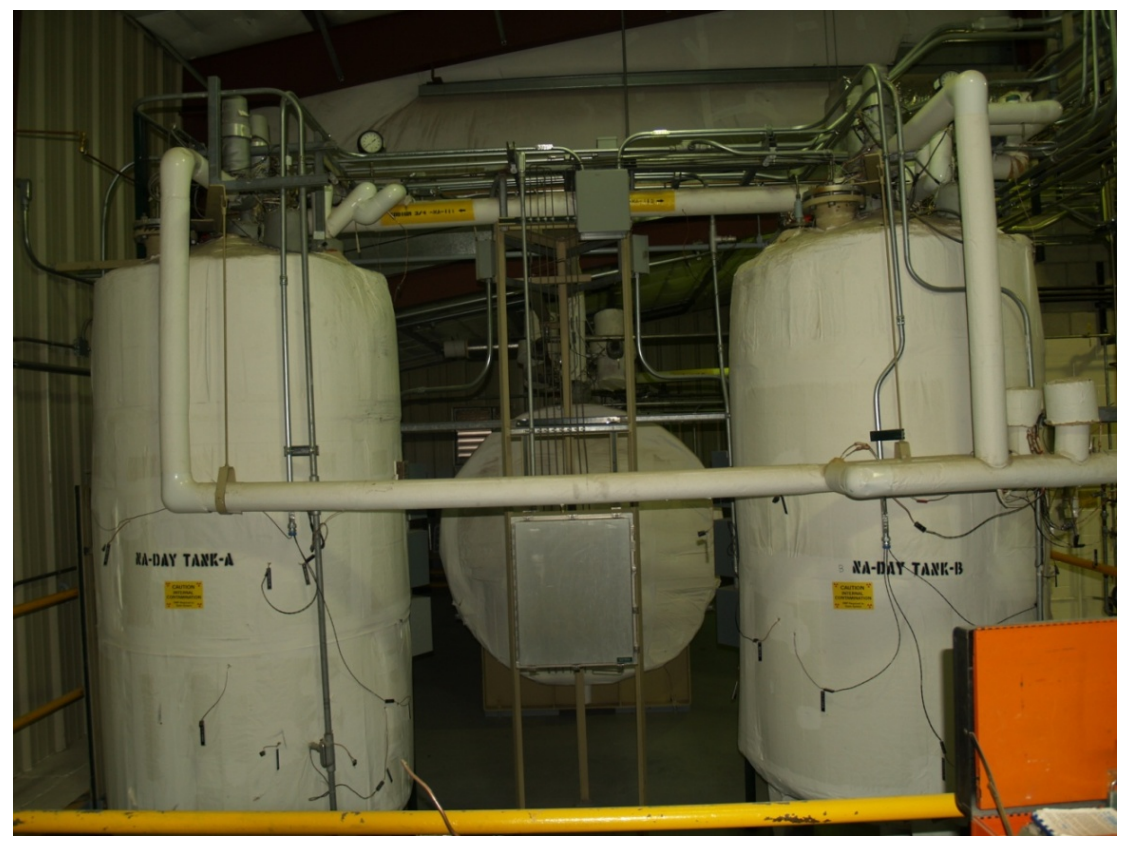

Figure 3. Sodium day tanks.

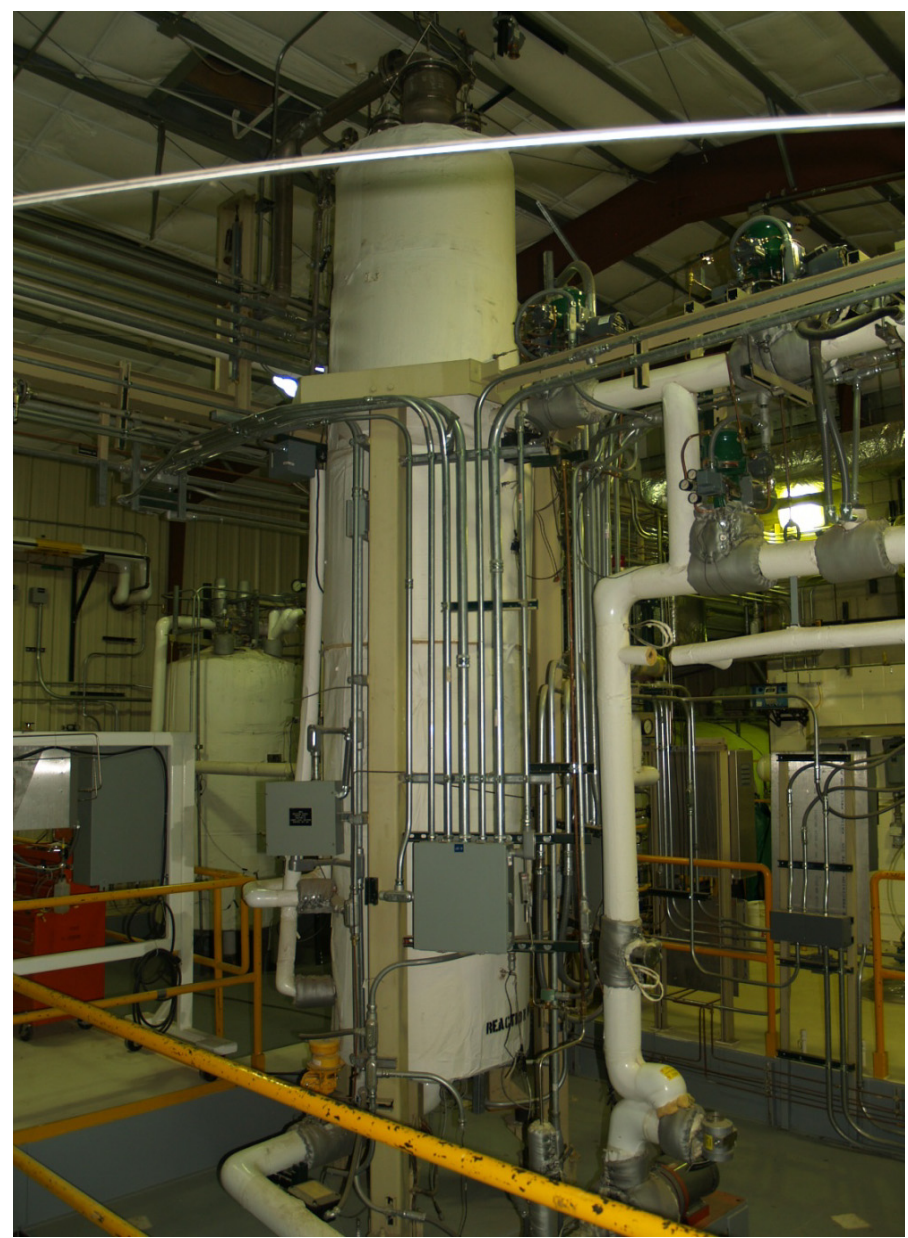

Figure 4. Sodium reaction vessel. 


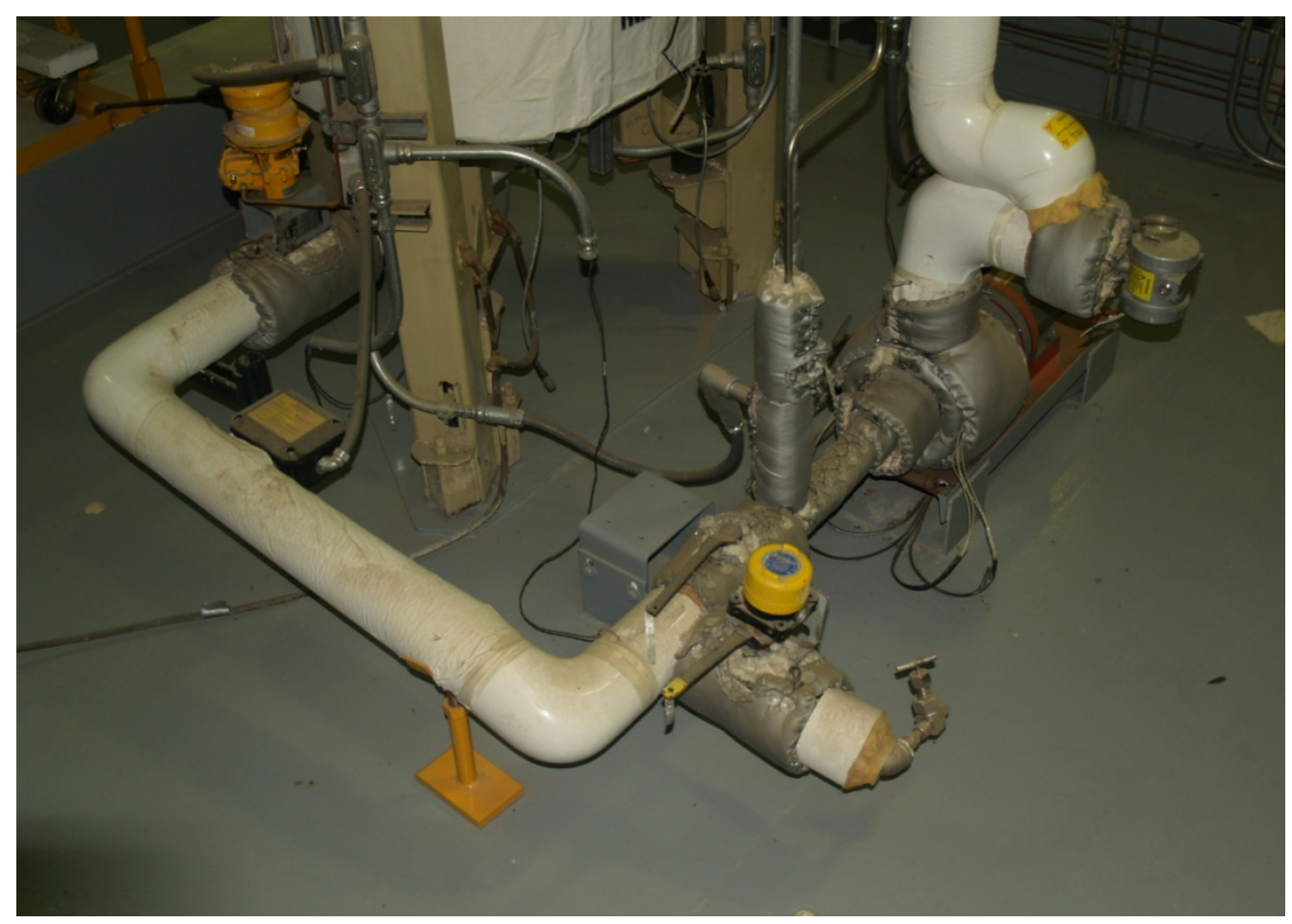

Figure 5. Sodium reaction vessel recirculation pumps and piping.

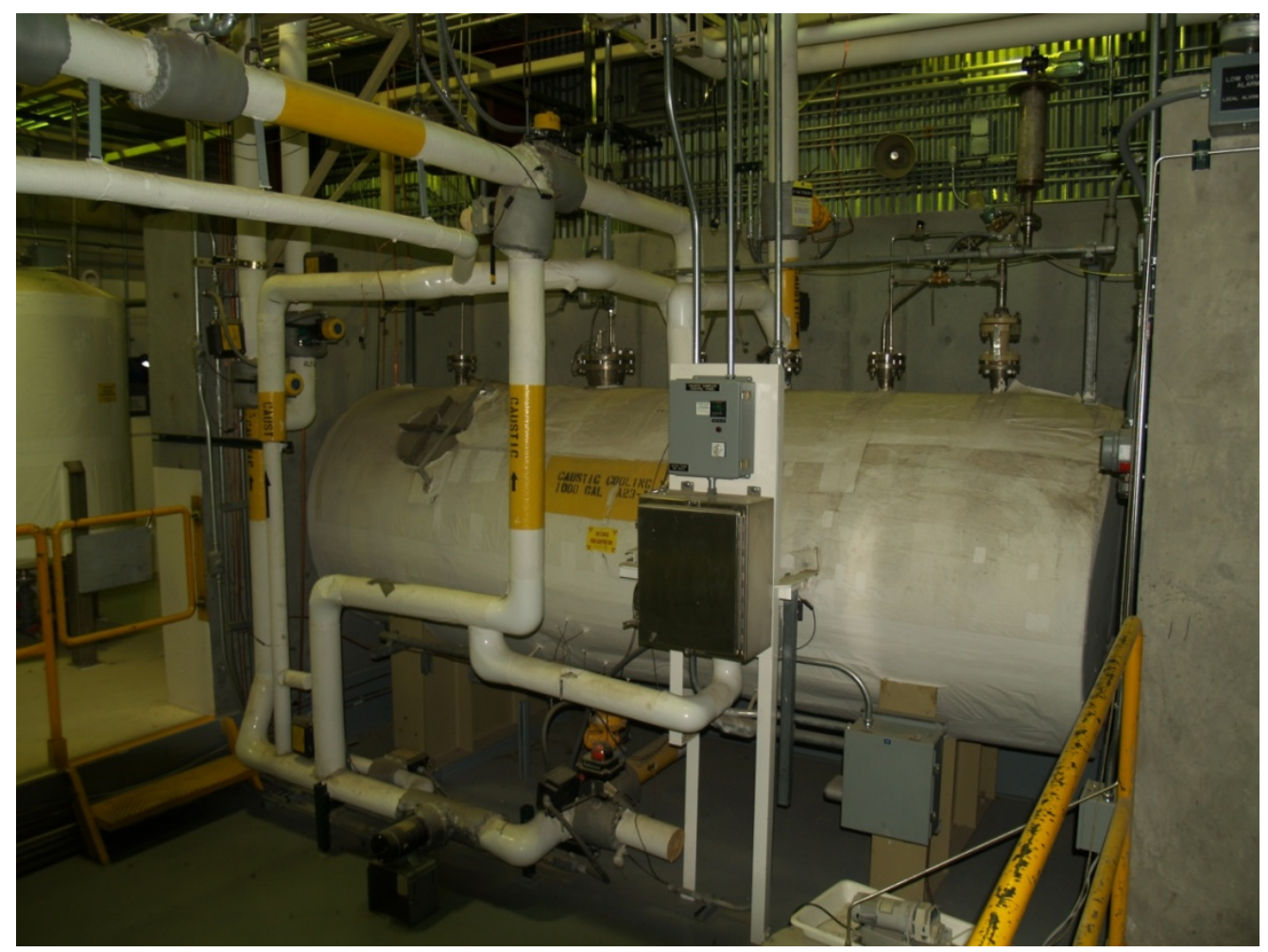

Figure 6. Caustic cooling tank. 


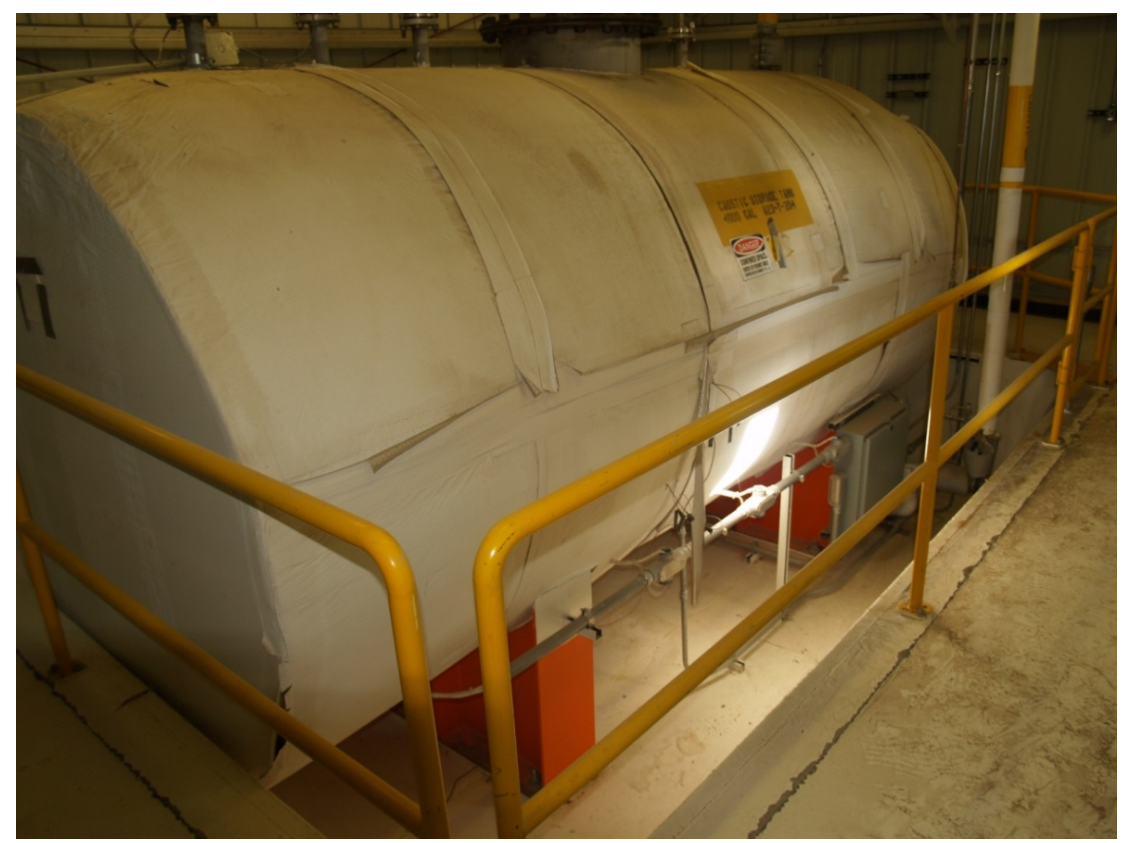

Figure 7. Caustic storage tank.

\section{SYSTEM SHUTDOWN PROCEDURES}

According to the entries in A Summary of the Operational and Maintenance Activities at the Sodium Processing Facility for the Period Covering December 1995 through March 2001 (Sandifer 2001), all processing of Experimental Breeder Reactor II primary sodium was completed on February 16, 2001. Once Experimental Breeder Reactor II processing was finished, the remainder of the FERMI sodium transferred to the Idaho National Laboratory (INL) was processed as a system flush ${ }^{\mathrm{a}}$. Processing of FERMI sodium was completed on March 5, 2001, at which time, a non-routine procedure was performed to minimize the residual amounts of sodium and caustic left in all tanks/containers at the Sodium Processing Facility. The Sodium Processing Facility was then shutdown to a facility standby status.

The non-routine procedure consisted of pressurizing the nitrogen system and forcing out and collecting as much residual material within the sodium transfer piping and storage tanks as possible. The process continued until the system pressure could not be maintained, indicating there was an insufficient quantity of sodium remaining to create a backpressure seal against the nitrogen purge.

Residual caustic in the reaction vessel was pumped from the bottom of the vessel and into the caustic cooling tank until pump vacuum could no longer be contained, indicating the reaction vessel had been evacuated to as low a level as possible. The residual caustic pumped into the caustic cooling tank during this process remains, and the tank level is monitored via an active bubbler measurement system.

Contaminated caustic was never stored in the caustic storage tank in MFC-799A. A clean, 50\% solution was pumped into the tank for initial system testing but was later pumped back out via the tank bottom drain. Pumping continued until suction was lost, indicating the tank is empty and any residual is limited to what is contained within the associated recirculation pump and lower piping connection.

\footnotetext{
${ }^{a}$ Conversation with Darrell Pfannenstiel on June 29, 2010, confirmed that the reason FERMI sodium was considered a system flush is because the FERMI sodium was less radioactively contaminated than Experimental Breeder Reactor II sodium. Actual activity readings are not available nor are they considered significant for purposes of this report.
} 
It is reasonable to assume that further draining of the system would require opening the tanks, pumps, and drains, which would be neither prudent nor cost effective. Residuals are considered minimal and isolated to readily identifiable locations.

The facilities have been well maintained since shutdown, with regular inspections. No evidence of leakage has been observed and regular checks of the caustic cooling tank bubbler measurements indicate that the tank level has not changed since system shutdown.

\section{RESIDUAL HAZARDOUS MATERIAL QUANTITIES}

Two documents provide information relative to residual hazardous materials remaining in the system in the Sodium Processing Facility. The first is the Materials and Fuels Complex Emergency Management Hazards Assessment (EHA-70), Appendix R (prepared in 2006). The second is the Sodium Processing Facility Systems Log, which is maintained in accordance with the requirements of the Materials and Fuels Complex Hazardous Waste Management Act Resource Conservation and Recovery Act (RCRA) Storage and Treatment Permit.

\subsection{EHA-70 Quantities}

\subsubsection{Sodium}

The MFC-799 sodium tanks are drained as low as practical and the remaining heels are estimated to be so low a quantity that sodium, while still likely present, is minimal and exempted from further evaluation as a hazard.

\subsubsection{Sodium Hydroxide}

EHA-70 estimates that there are approximately 200 to 240 gallons of $50 \%$ by weight solution of radioactively contaminated sodium hydroxide resident in the caustic cooling tank in MFC-799 and approximately 50 gallons of residual non-radioactive $50 \%$ by weight solution sodium hydroxide associated with the caustic storage tank in MFC-799A. This calculates to roughly $1,520 \mathrm{lb}$ and $315 \mathrm{lb}$ of dry caustic residual, respectively.

\subsection{Resource Conservation and Recovery Act Permit Quantities}

\subsubsection{Sodium}

Sodium quantities are not monitored because they are below reportable limits.

\subsubsection{Sodium Hydroxide}

- MFC-799A Caustic Storage Tank. This tank is not monitored in the permit because the material is non-radioactive and the volume is well below reportable quantities.

- MFC-799 Caustic Cooling Tank. The 50\% caustic solution in this tank is radiologically contaminated and subject to daily RCRA monitoring. Fluid-level monitoring is done using a calibrated bubbler measurement system in which the logs indicate a constant liquid volume of 450 gallons. This correlates to approximately $2,852 \mathrm{lb}$ of dry weight sodium hydroxide. This quantity does not agree with the EHA-70 number.

\subsection{Material Confirmation Measurements}

There is a disagreement between the EHA-70 and RCRA reported volume of contaminated residual caustic solution. Upon further investigation, it was determined that the volume recorded in EHA-70 was an approximate volume based on verbal information provided to the preparer(s) of the EHA rather than an 
onsite physical verification. The RCRA volume, on the other hand, is monitored daily via calibrated, realtime instrumentation. The RCRA volume is considered accurate and takes precedence over the EHA quantity.

Only the caustic cooling tank is instrumented for direct readings. The other tanks are sealed systems and would have to be opened and physically dipped or visually inspected to verify any residual levels. The risks and costs associated with such individual entries are not commensurate with the value of any additional information gained given what is already known and discussed above.

The caustic cooling tank bubbler measurement system was physically checked on an inspection visit made to the facility on June 29, 2010. The measurement system was operational and the calibration was current. The observed reading was 23 in., which correlates to a 450-gal liquid volume. According to facility management, this reading has remained constant since system shutdown in March 2001.

\section{SUMMARY AND CONCLUSION}

The processing system at the Sodium Processing Facility is well defined and the orderly process followed at shutdown gives assurance that the hazardous sodium and caustic materials internal to the system were drained to the lowest levels achievable.

Any sodium residual is limited to heels in the tanks, associated lower transfer piping sections, and is considered as such a minimal quantity as to be exempted from further consideration.

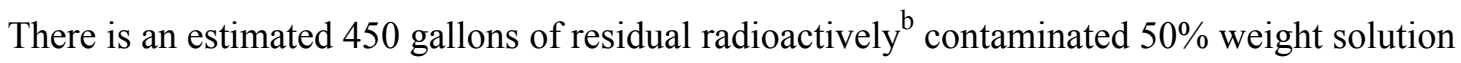
sodium hydroxide (caustic) contained in the caustic cooling tank in MFC-799. An additional estimated 50 gallons of non-radioactive $50 \%$ weight solution caustic is trapped in the lower pump and piping sections of the caustic storage tank in MFC-799A. In terms of dry weight of chemical, these liquid volumes translate to roughly $2,850 \mathrm{lb}$ and $315 \mathrm{lb}$ of sodium hydroxide, respectively.

The above estimates reflect maximum quantities and are less than $20 \%$ of the reportable quantity of the screening threshold in 40 CFR 302.4, Table 302.4. However, the quantities do exceed laboratory quantities (approximately 5 gal or $40 \mathrm{lb}$ ), and merit a National Fire Protection Association Health Hazard Rating of 3.

Based on the information, sufficient detail is known for the purposes of facility transfer and further characterization/verification is unnecessary.

\section{REFERENCES}

40 CFR 302.4, 2002, Title 40, "Protection of Environment," Part 302, "Designation, Reportable Quantities, and Notification," Section 302.4, "Designation of hazardous substances," Code of Federal Regulations, Office of the Federal Register.

DOE Guide 413.3-8, Environmental Management Cleanup Project, September 24, 2008, MFC Hazardous Waste Management Act) RCRA Storage and Treatment Permit, No. ID4890008952, dated August 16, 2004, and modified on October 2, 2008, U.S. Department of Energy.

DOE Guide 450.3-3, Tailoring For Integrated Safety Management Applications, U.S. Department of Energy, February 1997.

EHA-70, Appendix R, "Emergency Management Hazards Assessment for MFC-799, Sodium Process Facility, and MFC-799A, Caustic Storage Tank Building," Revision 0, Effective Date July 5, 2006, eCR Number 506092.

\footnotetext{
${ }^{\mathrm{b}}$ Per EHA-70, MFC-799/799A are less than Hazard Category 3 facilities.
} 
INL, 2009, Facilities Condition and Hazard Assessment for Materials and Fuel Complex Sodium Processing Facilities (SPF) MFC-799/799A and Nuclear Calibration Laboratory MFC-770C, INL/EXT-09-17292, Idaho National Laboratory, November 2009.

INL, 2010, Transition Plan for Multiple Facilities at the Materials and Fuels Complex, Advanced Test Reactor, Central Facilities Area, and Power Burst Facility, PLN-3352, Idaho National Laboratory, January 2010.

MFC Hazardous Waste Management Act (HWMA), RCRA Storage and Treatment Permit, No. ID4890008952, dated August 16, 2004, and modified on October 2, 2008.

Sandifer, V., 2001, "A Summary of the Operational and Maintenance Activities at the Sodium Processing Facility for the Period Covering December 1995 through March 2001," prepared by Van Sandifer, EBR-II/SPF Operations Manager.

\section{APPENDIXES}

Appendix A, Sodium Process Facility General Arrangement Drawing

Appendix B, Sodium Process Facility Sodium Process Piping and Instrumentation Drawings 
Appendix A

Sodium Process Facility General Arrangement Drawing

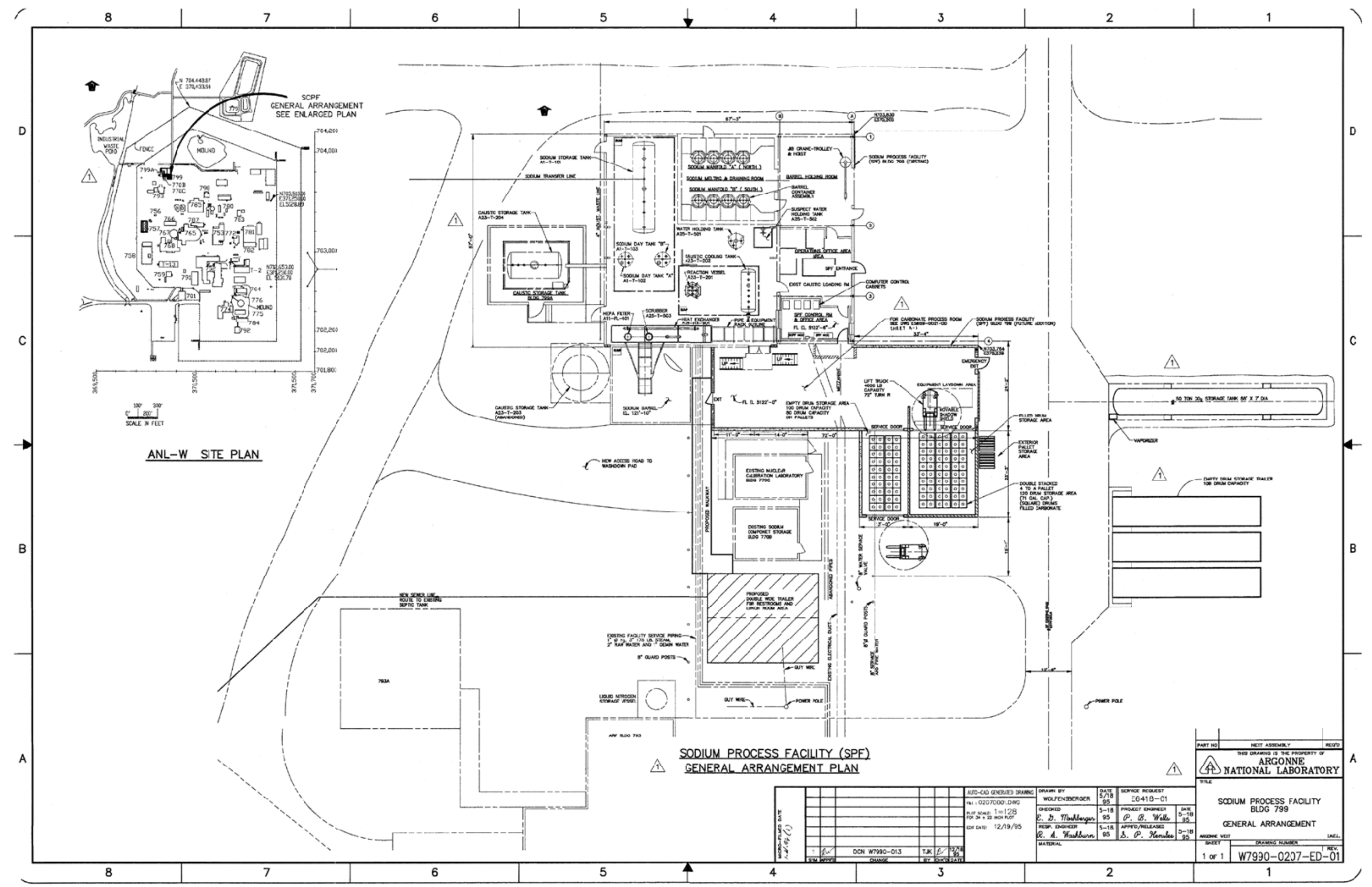


Appendix B

Sodium Process Facility

Sodium Process Piping and Instrumentation Drawings

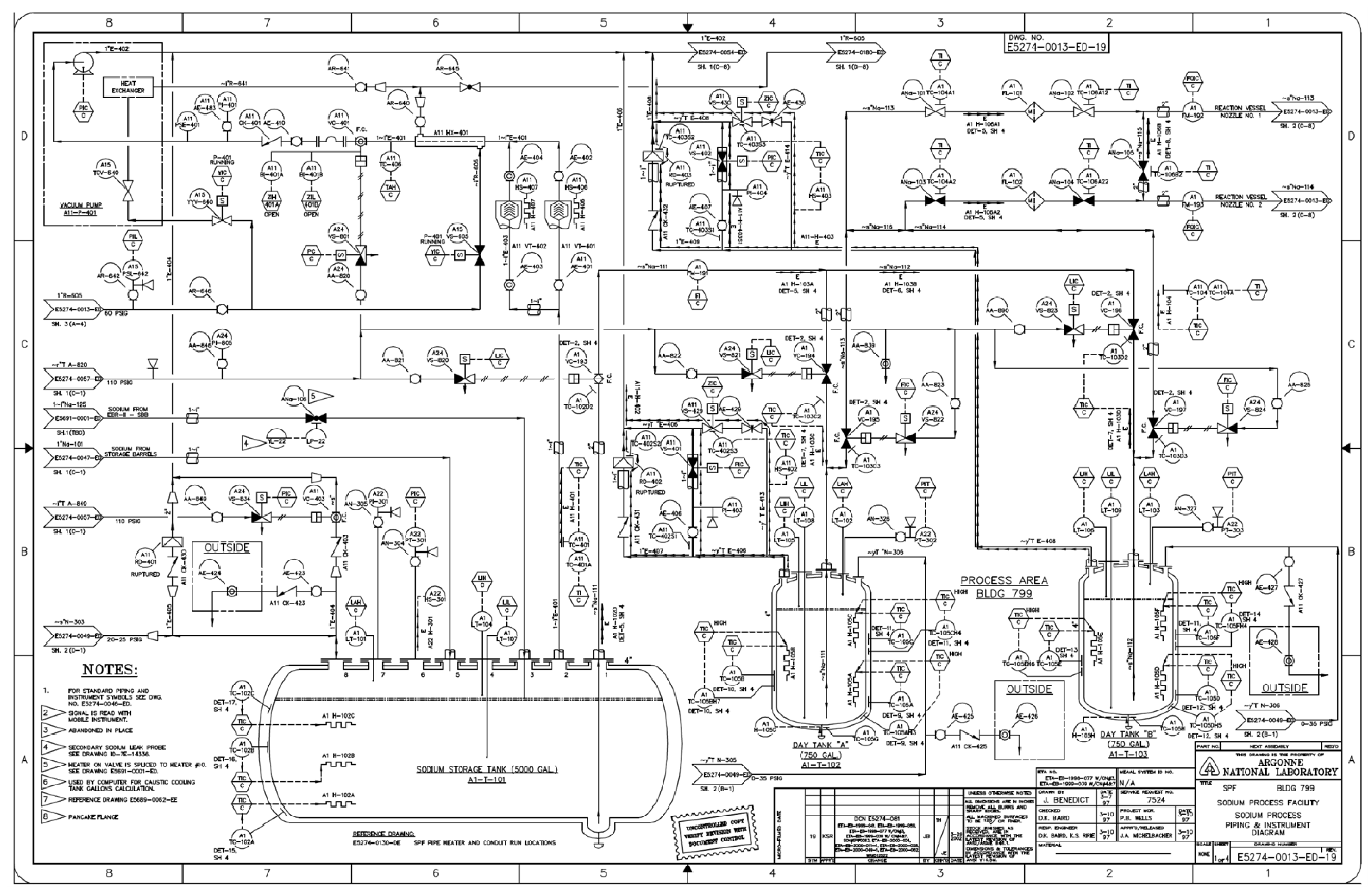




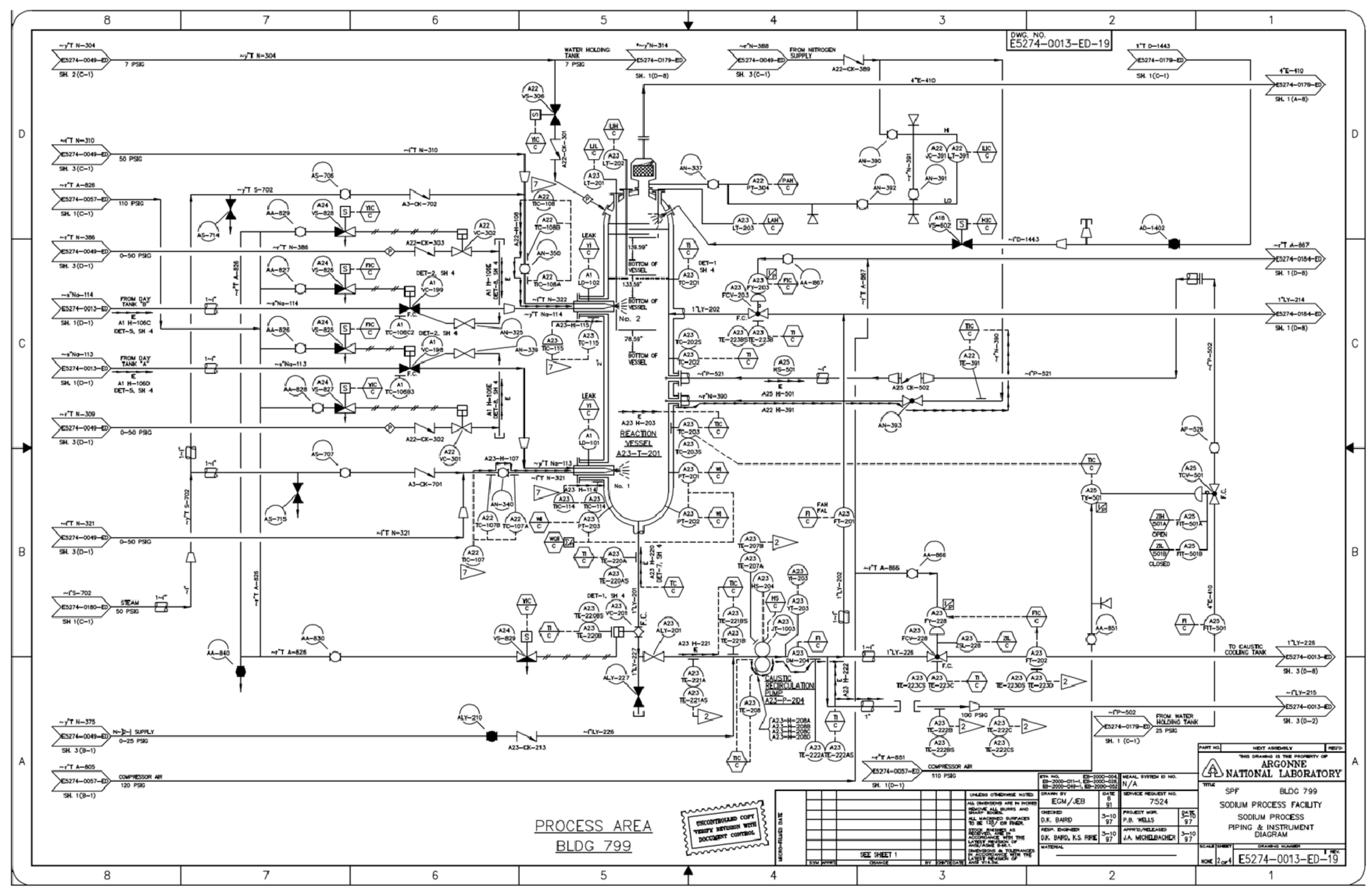




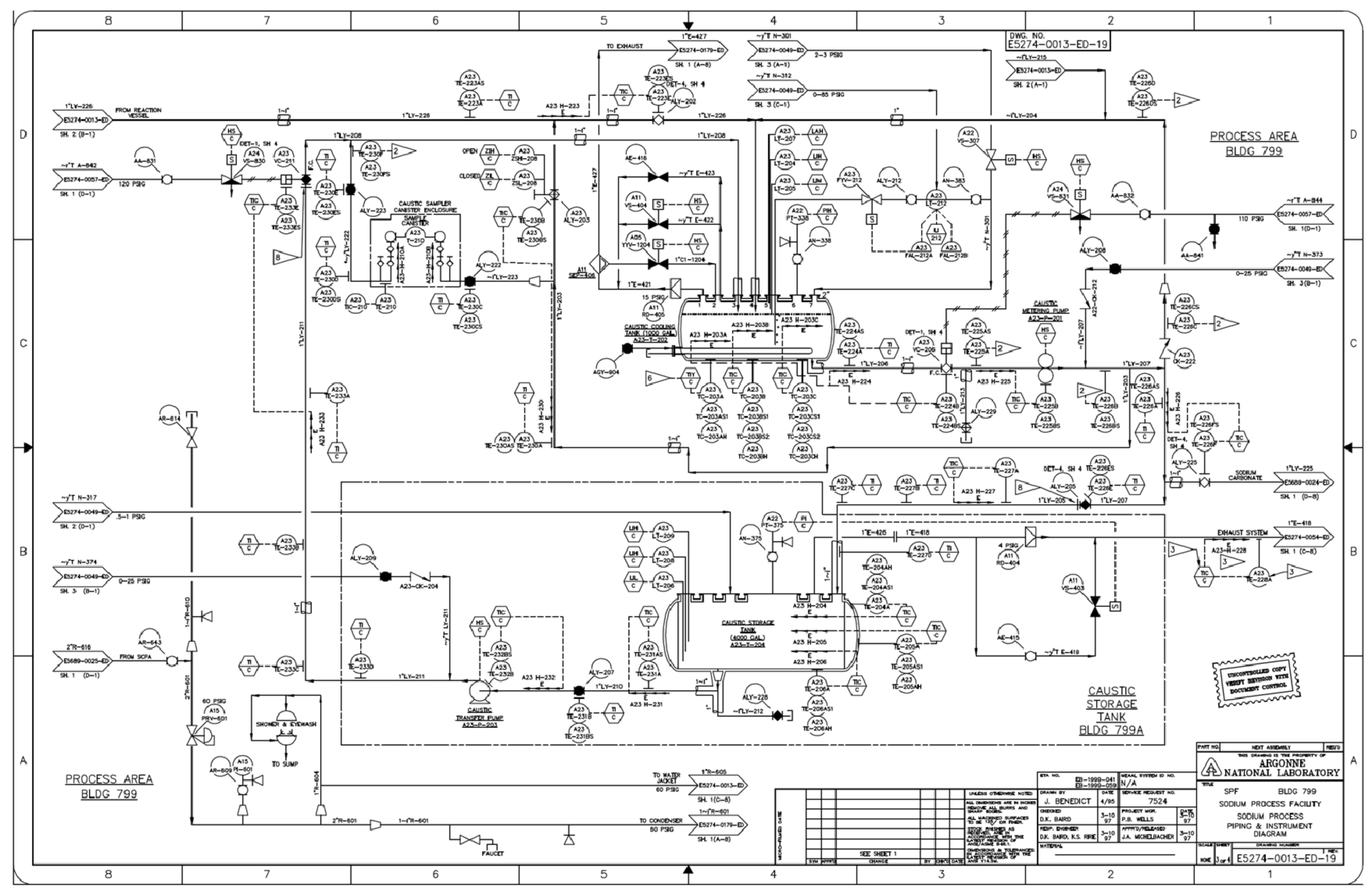




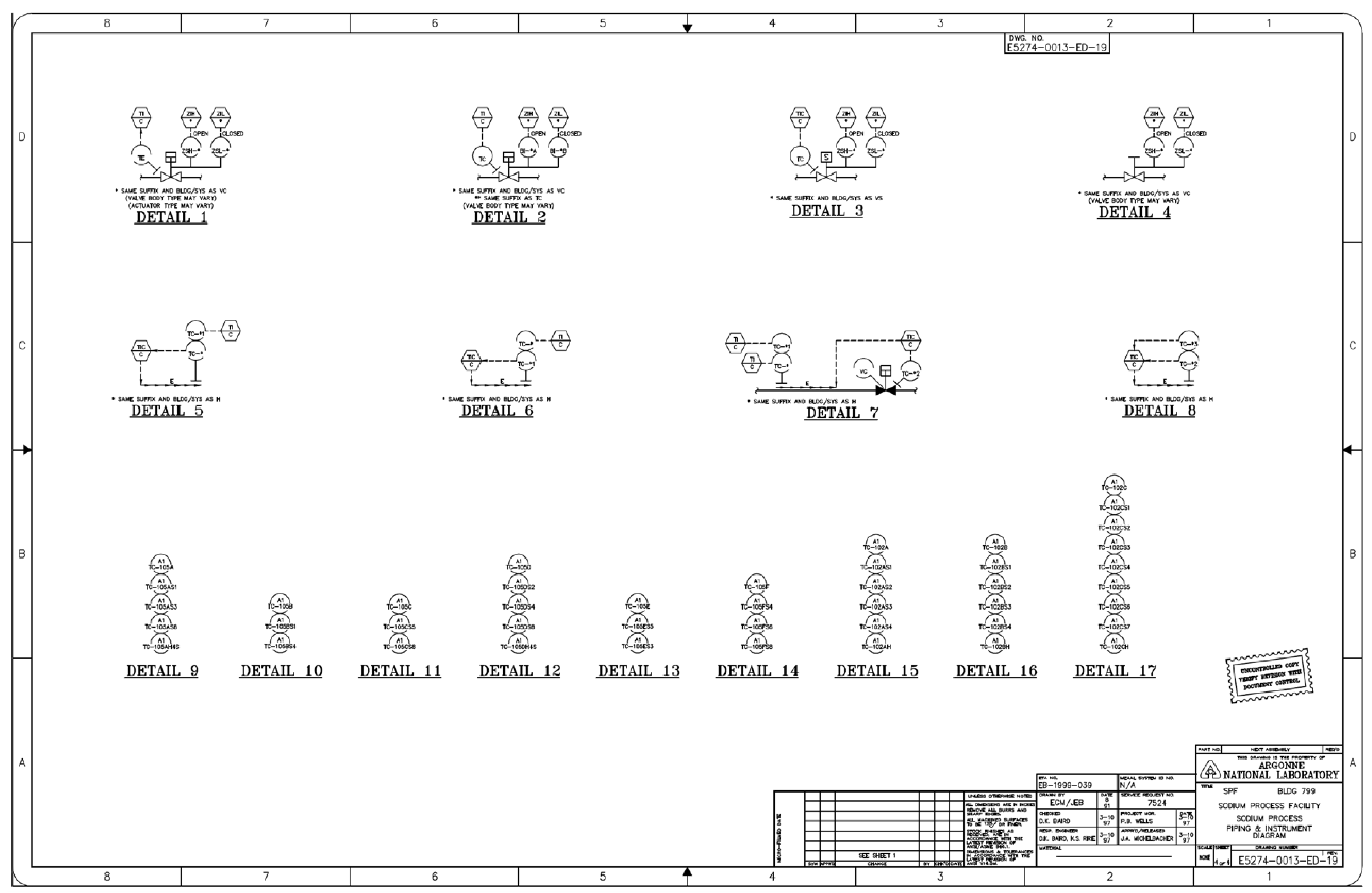

